How to cite this article:

Sun, P. H., \& Lee, S. Y. (2020). The importance and challenges of outcome-based education - a case study in a private higher education institution. Malaysian Journal of Learning and Instruction, 17(2), 253-278. https://doi.org/10.32890/ mjli2020.17.2.9

\title{
THE IMPORTANCE AND CHALLENGES OF OUTCOME- BASED EDUCATION - A CASE STUDY IN A PRIVATE HIGHER EDUCATION INSTITUTION
}

\author{
${ }^{1}$ Poi Hun Sun \& ${ }^{2}$ Sek Yan Lee \\ ${ }^{1}$ Department of Economics and Finance \\ ${ }^{2}$ Assessment and Accreditation, \\ Sunway University, Selangor, Malaysia
}

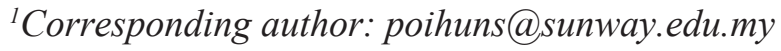

Received: 24/10/2019 Revised: 23/4/2020 Accepted: 3/7/2020 Published: 31/7/2020

\begin{abstract}
Purpose - Given the importance of quality assurance and the enhancement of curriculum in higher education institutions, it is vital to have a systematic process that measures students' performance objectively and effectively for continuous improvement of the programme/curriculum. The purpose of this study is to analyse the process of establishing an Outcome-Based Education (OBE) system in a business school of a private higher education institution in Malaysia. The importance and challenges of the OBE system are discussed, with some recommendations proposed for common issues.

Methodology - Document analyses and observations were conducted on ten undergraduate programmes in the business school of a private higher education institution from the year 2015 to 2019. This methodology was employed to assess and discuss the processes needed for the implementation of OBE, and highlights the importance and challenges of having an OBE system in the business school.
\end{abstract}


Findings - To ensure effective functioning of the process for implementing an OBE system, proper planning is required. Data from the OBE system and its utilisation are essential to achieve continuous quality improvement to the curriculum, and to offer assurance to the relevant stakeholders on the quality of graduates. Several steps were discussed in this study that provided guidance to other education institutions on the implementation of the OBE process. However, it is clear that the investment of time and effort is needed to ensure the smooth-running of OBE establishment and maintenance.

Significance - This study provided essential guidelines to relevant parties for the implementation of an OBE system in education institutions. The OBE system is needed to measure students' performance objectively and effectively, while enriching the students' learning experiences. This study highlighted some recommendations to the management of the education institution, policy makers, accrediting bodies and academics on the implementation of an OBE system in the education institutions.

Keywords: Outcome-Based Education (OBE), constructive alignment, curriculum, continuous quality improvement, quality assurance, educational accreditation.

\section{INTRODUCTION}

In the current economic environment, it is vital to have knowledgeable, creative, innovative, and valuable human capital that could drive the economy and country. It is believed that knowledge has the transformative power that could propel a nation. Hence, it is important to invest in the education system of the country.

In Malaysia, the Ministry of Education has always been the largest recipient of budget allocation from the federal government. It is estimated that roughly RM60.2 billion (equivalent to $19.1 \%$ of the total government expenditure) was allocated for the Malaysian education expenditure in 2019, while RM61.6 billion was allocated in 2018. This allocation has been vital to assist students and schools for funding and scholarships, facilities, developmental programmes and other functions (Ministry of Finance, 2018; Ministry of Finance, 2019). 
Despite the huge budget allocation to the Malaysian education sector, there is growing concern among employers with regard to graduates' career readiness in the job market. This includes incompetency among (potential) graduates, and the lack of knowledge displayed by most of these individuals (Kalianna \& Chandran, 2012). Thian, Ng, and Ewe (2018) highlighted the problems of the curriculum design framework that was developed, delivered and assessed to potentially understand the extent of graduates' capabilities and competencies.

Vighnarajah, Wong, and Abu Bakar (2009) criticised the examinationoriented nature of the Malaysian education system that encouraged students to develop a passive learning attitude. As a result, the concept of "having good results guarantee a good job" has been embedded into their minds. However, the adeptness to articulate the knowledge learnt and essential skills among graduates are still underdeveloped. Essentially, this has led the Ministry of Education in Malaysia to redirect the focus to an Outcome-Based Education (OBE) that not only emphasises knowledge acquisition, but also develop the essential skills to cope with the demanding job market and economic environment.

The quality assurance process to effectively measure students' performance poses challenges to higher education institutions. The higher education system in Malaysia is governed by the Malaysian Qualifications Agency (MQA). Its primary focus is to monitor the quality assurance practices in higher education institutions based on the Malaysian Qualifications Framework (MQF) - the national reference that guides Malaysian qualifications. The courses and programmes offered in higher education institutions are accredited by the MQA if they fulfil the framework and accreditation criteria. This provides assurance to stakeholders that the programmes are quality assured. Although higher education institutions are required to comply with the set of criteria and standards stated in the MQF, flexibility is given to education institutions to stay abreast to societal changes (Malaysian Qualifications Agency, 2017).

Since the current flexibilities are available to institutions, the MQA does not enforce any guidelines or documentation on the approaches needed to assess the outcomes stated in the MQF. In this circumstance, most higher education institutions do not assess students' performance on learning outcomes as they lack the 
appropriate mechanisms to collect and analyse assessment data in a systematic approach. Moreover, the institutions may find this process to be a waste of time and effort (Reich, Collins, DeFranco, \& Pieper, 2019a), while some may argue that the process is too task-oriented (Kennedy \& Birch, 2020). These are the common issues encountered by most higher education institutions in Malaysia. Hence, there has been limited reporting on students' performance that are available, while assessments on continuous quality improvement have been absent in most cases.

In addition to having accreditation from MQA, some schools and/or programmes seek other accreditation from professional bodies. The accreditation from professional bodies offer significant recognition to the schools and/or programmes for their appropriate and effective assurance of learning process. This includes identification of learning outcomes, relevant teaching and learning methodologies, assessment setting, and performance analyses for the continuous improvement and quality enhancement of the courses and programmes.

In a study conducted by Roller, Andrews, and Bovee (2003), accreditation received from professional bodies and implementation of proper OBE process have provided various benefits to business schools. Moreover, obtaining these accreditation led to a positive impact on staff recruitment, marketing and promotion, research publications and consultancy work, resource planning, student learning experiences, and the reputation of business schools. Different institutions utilised the accreditation status for different purposes; predominantly, it was a way to improve competitiveness in the higher education sector.

Conversely, Roller et al. (2003) and Gunarathne, Senaratne, and Senanayake (2019) argued that some institutions may delay or not seek any accreditation status from professional bodies, as the process of obtaining one consumes time and resources. Obtaining accreditation from professional bodies require reviews and restructuring of programmes and courses, and furthermore, suggests that the accreditation may not guarantee students' quality learning experiences or improve the competitiveness of business schools. Additionally, acquiring accreditation from professional bodies requires monetary investments, whereby not all institutions are able to afford it. 
In Malaysia, whether the accreditation is obtained from the MQA or professional bodies, it is important to recognise the quality of modules and/or programmes in the education institutions. Most higher education institutions will identify relevant expected learning outcomes, teaching and learning methodologies, and assessment when developing modules and/or programmes in Malaysia. Nevertheless, the assessment of students' performance is lacking in most cases. Without an appropriate and systematic measurement of students' performance, it is difficult to conclude on whether higher education institutions have achieved what is needed under OBE.

Similarly, higher education institutions have no means to present their graduates' achievements of their courses' learning outcomes to stakeholders, particularly employers. This is highlighted by Gunarathne et al. (2019) and Hill and Wang (2018), and further asserted the importance of OBE and constructive alignment processes. The OBE and constructive alignment processes are important to ensure that the authority, accreditation bodies and higher education institutions are aware of the guidelines, standards and principles when they develop and revise the qualification framework. Therefore, this study intends to highlight the process of setting up the OBE system in the business school of a private higher education institution in Malaysia by applying the OBE requirements from the MQA. Moreover, the importance and challenges encountered in the process of setting up the OBE system can be assessed through document analyses and observations. Some recommendations are also suggested as guidelines to other higher education institutions to address several common issues encountered during the implementation of the OBE system.

This study provides a guideline to higher education institutions for the implementation of the OBE system as most higher education institutions in Malaysia lack the systematic process to measure learning outcomes and students' performance. The outcomes from the OBE process is important to restructure the curriculum to improve students' learning experiences. Furthermore, it is hoped that the authorities, accreditation bodies and higher education institutions can further explore different pedagogical and curriculum methods for OBE approaches (Matthews \& Mercer-Mapstone, 2018), while academics could investigate various other approaches to measure students' performance (Aamodt, Frølich, \& Stensaker, 2016). 
With the proper implementation of the OBE process, the quality of teaching can be assured, and would subsequently improve the reputation of higher education institutions.

\section{LITERATURE REVIEW}

According to Roller et al. (2003), accreditation of business schools provide various benefits. However, some higher education institutions may not seek accreditation due to time and resource constraints. In the higher education sector, accreditation from the MQA requires compliance with the MQF, whereby the implementation of OBE in programmes of study is imperative.

According to the Malaysian Qualification Agency (2013), OBE is defined as "an approach to education that begins by clearly focusing on high-quality, culminating demonstrations of significant learning in context and organising everything in an educational system around what is essential for all students to be able to do successfully at the end of their learning experiences. This means starting with a clear picture of what is important for students to be able to do, then organising the curriculum, instruction, and assessment to make sure this learning ultimately happens to all students." (p. ix)

Based on the definition of OBE, it is highlighted that the main purpose of its implementation is to help students achieve learning expectations through curriculum design and to ensure students' performance is measured objectively. According to Djoundourian (2017) and Kim and Helms (2016), OBE allows higher education institutions to improve students' learning experience and serves as a guide to enhance the quality and effectiveness of the programmes and modules. An effective OBE system allows institutions to plan, report and monitor study programmes and modules. Implementation of the OBE system may grant the required accreditation and give confidence to stakeholders on the quality of graduates and programmes in these institutions. Ultimately, this will improve the reputation of institutions.

Kalianna and Chandran (2012) asserted that the OBE implemented in the education sector in Malaysia is significant to restructure the programmes, modules, teaching and learning methodologies, 
assessment and performance measurement. These changes are important to enhance students' learning experiences and improve competencies of (potential) graduates. When assessing the OBE implementation in higher education institutions in Malaysia, Kalianna and Chandran (2012) suggested that the OBE system should focus on three significant aspects: (i) outcomes; (ii) curriculum design; and (iii) responsibility of academics and learners. In addition, the study utilised the Computerised Outcome-Based Education System (COBES) to analyse the results from entrance and exit surveys, and concluded that it was important to continuously improve and assess all aspects of the modules and programmes despite achieving the learning outcomes. This is because learning is an ongoing and evolving process. The achievement of students in the entrance and exit surveys were not indicative of future achievement and students' competency at the workplace.

Based on the study by Spady and Marshall (1991), three types of OBE systems were compared: Traditional OBE, Transitional OBE and Transformational OBE. It was further suggested that the Malaysian education system relies heavily on Transitional OBE, with the emphasis on the development of essential skills such as critical thinking and problem solving, communication skills, technological skills and other soft-skills. Consequently, curriculum enhancement should be done regularly to promote skills and competencies that would equip graduates with knowledge and values. These outcomes are observed in Transformational OBE, in relation to the design/ redesign of modules, programmes and/or intended outcomes, and the opportunity and support for successful learning journeys. However, different students may have different preferences and methods of learning.

Furthermore, Spady and Marshall (1991) further suggested that there was a gap between the course and programme offerings in the education institutions, and the industry's expectations. This conclusion was consistent with the findings by Gunarathne et al. (2019). Matthews and Mercer-Mapstone (2018) stated that academics may have different opinions on curriculum development as they tend to be more focused on unit-level activities and syllabus, where scaffolding was lacking in these activities. Therefore, it is important to facilitate scaffolding and the progressive development of skillsets for students to align with the expectations of different 
stakeholders. This can be achieved through the implementation of an OBE process.

Dragoo and Barrows (2016) suggested that the expectations of the industry should be aligned with and integrated into the education system as they are integral in producing competent (potential) graduates, as required under OBE. Expectations from the industry can serve as a guiding framework, and be embedded in modules through course content, learning methodologies and assessment.

Spady (1994) asserted that the outcomes from OBE should be able to reflect the learning process and context, regardless of the model used. This indicates that the teaching and learning methodologies, and assessment setting should be hierarchical, where it is based on intended learning outcomes at different levels.

However, establishing an OBE ecosystem in an education institution has always been complicated. To ensure the ecosystem is sustainable, it is essential for all academics and administrative staff to adapt to these new changes, while there would need to be substantial resource allocation due to the increased expenses and effort (Djoundourian, 2017). Hence, a proper OBE implementation plan should be in place.

From the discussion of the implementation process of learning outcomes in the university curriculum as a model and operational pathway, Hill and Wang (2018) emphasised that the development of learning outcomes is not a one-man show. A committee needs to be established to ensure the smooth operation of the OBE process. The committee must be equipped with skills to assess the process, and work closely with the relevant stakeholders to ensure alignment between learning outcomes, syllabus, delivery methods, assessments and industry's expectations. At the same time, transparency is needed for academics to devise better plans with regard to the delivery methods in the institutions. It is important to provide the necessary evidence of learning outcomes for continuous quality improvement. However, Hill and Wang (2018) concluded that the implementation of OBE in institutions is a long-term project that would take considerable time and effort.

Matthews and Mercer-Mapstone (2018) examined and compared the perceptions of students and academics on learning outcomes. 
They suggested that there should be alignment between students' and academics' perceptions of skillsets as part of the OBE to obtain a more holistic picture of the expectations from both parties. Essentially, this would lead to a more systematic curriculum design and development that could enhance students' future employability. Hence, it is expected that collective planning and sharing of best practices should be developed to help overcome the differences in expectations between academics and students.

In a comparative study of quality assurance and learning outcome approaches in Norwegian higher education institutions by Aamodt et al. (2016), it was suggested that there was a need for more effective and efficient delivery of the syllabus due to increasing globalisation. Although both quality assurance and learning outcome approaches are implemented for different purposes, these approaches are indifferent to ensure quality teaching and learning. Furthermore, it was perceived that the learning outcome approach is more relevant to academics. Hence, it is much more accepted. However, there has been growing concern on whether this approach was handled well, as no concrete outcomes were observed. This approach will become a standardised procedure in the long run, where academics may experience reduced flexibility and creativity in its delivery. It is also viewed as another policy that would require compliance from higher education institutions.

In OBE, there is a need to associate the curriculum, teaching and learning methodologies, and assessment with learning outcomes to improve students' performance and learning experiences. Primarily, this refers to constructive alignment. This is supported by Reich et al. (2019a) and Gunarathne et al. (2019) and further asserts that this is part of the continuous quality improvement that can help academics understand and uncover the methods of teaching and assessing students in a dynamic environment. It is also suggested that the $\mathrm{OBE}$ and constructive alignment processes should include relevant stakeholders such as industry experts and alumni for insights and suggestions on the programmes. Upon successful implementation of constructive alignment and OBE processes, courses and programmes will be more flexible and dynamic, while remaining compliant with the quality and standards of the industry and authority. At the same time, students will be able to take full responsibility for their studies more effectively as students will feel more engaged when academics 
are aware of the need for quality teaching and learning (Almarghani \& Mijatovic, 2017).

According to the Malaysian Qualifications Agency (2017), OBE "specifies the desirable outcomes or abilities which students should be able to demonstrate upon completion of an educational programme. The quality of a programme is ultimately assessed by the ability of its graduates to carry out their expected roles and responsibilities in society. This requires a clear statement of the competencies, i.e., the practical, intellectual and soft skills that are expected to be achieved by the student at the end of the programme. The main domains of learning outcomes cover knowledge, practical and social skills, critical and analytical thinking, values, ethics and professionalism. The levels of competency of these learning outcomes are defined in the Malaysian Qualifications Framework (MQF)" (p.8). The following statement suggests that the implementation of constructive alignment in curriculum design is required to support the OBE approach; "a programme is designed and delivered to facilitate the attainment of a set of desired learning outcomes. It starts with a clear definition of the intended outcomes that students are to achieve by the end of the programme and supported by appropriate instructional approaches and assessment mechanisms (constructive alignment)" (MQA, 2017, p.9).

Thian et al. (2018) defined constructive alignment as a precise alignment of teaching and learning methodologies and assessment to achieve the intended learning outcomes in modules and programmes. Constructive alignment is a significant process in the implementation of OBE. By incorporating constructive alignment in modules/ programmes, the evaluation of students' performance will be more meaningful. Additionally, this enables systematic curriculum design and review, and students' learning experiences to improve under various teaching and learning activities and assessment. However, some studies have indicated that most academics are reluctant to change despite students' performance. This may be due to an inadequate knowledge of constructive alignment, overwhelming workload among academics, and the education institutions' focus on research output.

Gibbs and Habeshaw (1992) proposed that the enhancement of students' knowledge and skills are more meaningful when students 
could recall the knowledge and skills from the relevant course guides, learning outcomes, syllabus and content, assessment and delivery methods. However, students and academics are unwilling to put in the effort due to time and resource constraints. However, Gibbs and Simpson (2004) concluded that the assessment is more meaningful and provides more support to students' learning experiences if it can measure the range of the students' skills and abilities. Since assessment is a better indicator for students' achievements, coursework is considered a good assessment tool in most cases.

To understand the expectations of learners and academics, Barradell (2012) proposed to sequence out and integrate the curriculum content systematically. This is a critical scaffolding process that could identify the learning processes needed for students to support and enhance their learning experiences, and establish a sense of responsibility. Moreover, scaffolding is important to ensure the continuity and sustainability of courses and programmes that could be done through curriculum mapping (Matthews \& MercerMapstone, 2018; Reich et al., 2019a). Kember (2001) suggested that the integration of teaching and learning activities into the syllabus is vital to transmit the necessary information.

Regarding the assessment of students' performance, the type of assessment should reflect the appropriate level of sophistication, the learning outcomes of the modules/programmes, and the resources needed such as credit hours and finances. Proper measurement methods should be developed and communicated to the students. These should provide credibility in assessment design (Dragoo \& Barrows, 2016; Matthews \& Mercer-Mapstone, 2018). Moreover, Spady (1994) asserted that the assessment used should be based on different levels of complexity, generalisability and significance that would reflect the different levels of competency. Essentially, it should start with structured tasks/assessment to test lower-order competencies and outcomes, followed by semi-structured and unstructured tasks/assessment that tests higher-level and complex competencies and outcomes. Students should be given different roles and assessments to enhance their learning experiences. Consequently, over-assessment of student learning can be avoided (Matthews \& Mercer-Mapstone, 2018) as the assessments could be mapped to the intended learning outcomes through formative and summative assessment (Reich, Collins, DeFranco, \& Pieper, 2019b). 
As suggested by Koh, George, Pak, Liow, and Khor (2014) and Spady (1994), the selection of assessment can be expanded to taskbased learning as community service learning can be utilised as a curriculum delivery tool that could be incorporated into major curriculum domains in institutions. The use of this assessment would enable students to practise their skills through active learning, while incorporating the knowledge and skills learnt in a classroom setting. It is hoped that the skills developed will be beneficial across all industries. The learning activities should constantly be reviewed to better reflect the intended learning outcomes in the modules/ programmes.

Djoundourian (2017) asserted that it is essential to identify specific learning outcomes, modules and programmes, and assessment types during the assessment planning. Moreover, there is no significant difference between home-grown assessments and standardised packages as the assessment is carried out to identify the level of knowledge and problem-solving skills gained by students. The results of the assessment should be analysed in order to establish a proper benchmark for comparison purposes.

Kennedy and Birch (2020) observed the implementation of OBE in a policing degree using two courses. Before the implementation of the OBE approach, negative feedback from students were received on the use of teaching and learning methodologies, assessment, and the personalities of academics. As the OBE was implemented in stages, it was observed that the students were more engaged in learning and provided good feedback. Academics have gained a better understanding on the needs to conduct a meaningful session by taking into consideration the relevant teaching approaches, change in personalities, interactions with students, and other factors. However, it was further suggested that the OBE process is mainly task-oriented, while learning outcomes are quantified to present the relevant outcomes. Therefore, OBE may not be applicable to human services professions.

On the other hand, Gunarathne et al. (2019) and Aamodt et al. (2016) indicated that despite the importance of having a proper process to ensure quality assurance and an effective measure of students' performance, it is vital to consider the challenges of implementing OBE. Over-emphasis on the standards and approaches may not only 
restrict creativity in teaching and learning, but would also increase the burden on academics, especially if there are limited support systems, mechanisms and resources, and a lack of planning during the implementation process. Furthermore, it may also compromise the quality of delivery of courses and assessment by academics. However, different parameters of OBE approaches may produce different outcomes. Hence, it is suggested that more research is needed to further explore the challenges and opportunities of OBE approaches to help the development and adoption of OBE in the future.

\section{METHODOLOGIES}

The main purposes of this study are to: (i) discuss the implementation of the OBE process; and (ii) analyse the importance and challenges of OBE approaches. This study was conducted at a business school in a private higher education institution in Malaysia, whereby the school is in the midst of implementing the OBE process as a requirement to earn accreditation from international professional bodies. The business school has no experience with the processes of implementing the OBE approach, making it an ideal subject for case study research (Aamodt et al., 2016; Gunarathne et al., 2019; Kennedy \& Birch, 2020).

This study employed a case study approach to conduct in-depth analysis on the implementation of OBE. This method was chosen to explore the research questions that would not need a control for behavioural events, as the people are still accessible and are able to recall events accurately (Gunarathne et al., 2019). Document analyses and observations were conducted on ten undergraduate programmes in this business school from the year 2015 to 2019. The main reason for the selection of the ten undergraduate programmes in this institution was due to the large number of courses available in the undergraduate degrees, the diverse background of the students, and the involvement of academics. These factors provided the opportunity to observe the dynamic behaviour of stakeholders within the different settings of courses and curriculum.

The documents, such as standards and reports, were analysed without a computer-aided programme to identify the consistencies and flaws 
in the OBE processes (Aamodt et al., 2016; Dragoo \& Barrows, 2016; Gunarathne et al., 2019; Kennedy \& Birch, 2020; Thian et al., 2018). The analyses of documents were essential at the initial stages of implementing the OBE system as changes were always being made to the system (Barradell, 2012). Consequently, the analysis enabled the identification of the requirements for a computerised system that could automate data collection and streamline the analysis and reporting.

Observations and questioning were conducted on the academics and administrative staff to identify outcomes and challenges of the OBE process. This was important as it allowed insight and suggestions to be collected from academics and administrative staff that would ensure the successful implementation of the OBE process (Barradell, 2012; Hill \& Wang, 2018; Reich et al., 2019a).

\section{FINDINGS}

In this section, the findings on the OBE implementation processes will first be discussed, followed by a discussion on the importance and challenges of the implementation of OBE approaches. Some recommendations are included to manage common issues that were identified during the implementation of the OBE process.

\section{OBE Implementation Processes}

OBE is a transformation process that helps students to develop different skills at different levels, and ensures that their performance are measured accurately to enhance the quality of the programmes and graduates (Barradell, 2012; Gunarathne et al., 2019; Reich et al., 2019a). This section discusses the OBE implementation process at a business school in a private higher education institution.

The first step in setting up the OBE process is to establish an OBE task force. The task force should consist of academics and administrative staff who are equipped with the relevant OBE skills to develop working models for implementation (Hill \& Wang, 2018). Proper planning and evidence on the OBE process should be carried out by this task force for analysis before presenting the relevant facts to the stakeholders. 
For the second step, the OBE task force should review the vision and mission of the school. This is essential as each institution has its unique identity and mission statements that determine the type of programmes offered, and the attributes of the institutions' graduates (Djoundourian, 2017). The programme educational outcomes (PEOs) and programme learning outcomes (PLOs) should also be reviewed to comply with the MQF learning domains, while the modules selected in the programmes must support the PLOs and complement the outcomes at the module level. Provisions on specific outcomes at a module level will help facilitate the analysis of assessment data. This will ensure continuity, sustainability and quality of programmes through scaffolding, and subsequently assure consistency among academics (Hill \& Wang, 2018; Reich et al., 2019a). As suggested by Reich et al. (2019a), the learning outcomes must be relevant, measurable, timely, specific and attainable.

After reviewing the vision and mission statements of the institution, PEOs, and PLOs of the programmes, it is important to create a curriculum map that would indicate the association of each module to the PLOs. From the curriculum map, the task force will be able to identify suitable modules that requires the specific assessment for data collection. Initially, the common core modules enrolled by the students across different programmes are selected. This is contrary to the approach adopted by Djoundourian (2017), where education institutions were advised to select any modules and assessment that can fulfil the relevant objectives.

For the third step, the courses for assessment and the types of assessment available were considered, and included direct and indirect assessments. Direct assessment is important to assess students' learning experiences by taking into account the syllabus, teaching and learning methodologies, types of assessment, learning hours and other components. These are observed and monitored in the classroom setting. Indirect assessment, such as employers' satisfaction and graduate job placements, is a method to obtain feedback from external stakeholders on the quality of students and/ or graduates to help improve the programme (Djoundourian, 2017; Reich et al., 2019b). Therefore, for assessment common courses such as Community Project (Koh et al., 2014) and Internship were also selected, along with the common core courses taught in the classroom-settings. 
For the fourth step, course learning outcomes for the selected courses were reviewed. This is to ensure that the teaching and learning methodologies, and assessment can be mapped more systematically that could provide evidence on the OBE process and serve as informed teaching and industry feedback (Reich et al., 2019b). In total, there were eleven courses selected, and these were classified to the nine PLOs at the undergraduate level studies in this business school.

For the fifth step, rubrics were developed to provide standardisation for the measurement and evaluation of students' performance. This is in line with the study carried out by Reich et al. (2019b) that suggested a fast and proper evaluation of students' performance can be used for OBE reporting. At this stage, coursework is selected over the final examination, as coursework can be used as a tool to measure knowledge, and assess problem-solving and other essential skills among students. This is further supported by Rust (2002); and Gibbs and Simpson (2004), and asserts that the final examinations emphasise knowledge and problem solving skills, but not essential skills. Comparatively, coursework is considered a much better method of assessment as it can measure a wider range of skills and abilities, and is considered a better indicator for students' learning processes and experiences.

The rubrics developed were the results of the efforts from the academics involved. Several pilot tests using the samples were conducted to fine-tune the rubrics. Through these tests, flaws were identified and actions were taken to enhance the analyses of assessment data. As supported by Kim and Helms (2016) and Reich et al. (2019b), testing was conducted to ensure that the rubrics developed can serve the grading guide in schools and eliminate bias. Furthermore, it improved the robustness of the analysis by comparing the results across modules in different programmes. The rubrics generated are generic, and provide flexibility to the academics to make the necessary changes when they adopt these rubrics in their modules. Concurrently, the rubrics enabled the performance of students to be compared and used for benchmarking purposes.

Using these rubrics, data on the students' performance were collected and analysed. The results are then compared to the learning outcomes and the benchmark for improvement. Based on the five-scale grading 
system $^{1}$ in this education institution, a threshold of $25 \%$ was set, where students who obtained "Weak" and "Poor" grades shall not exceeding the $25 \%$ threshold.

For the sixth step, the task force, academics and programme coordinators are required to analyse the performance of students based on the syllabus, teaching and learning methodologies, and types of assessment. Academics and programme coordinators are required to propose initiatives that could improve the overall performance of students and students' learning experiences in the coming semesters. All information and discussions were documented that would allow the reassessment of students' performance in the future. Furthermore, this creates awareness among academics for continuous improvement of courses and/or programmes to improve students' learning experiences, as supported by Kim and Helms (2016) and Reich et al. (2019b). Moreover, Reich et al. (2019b) and Hill and Wang (2018) suggested that the results be shared with other relevant stakeholders such as industry experts to identify the strengths and weaknesses of the courses or programmes offered in institutions.

\section{Importance and Challenges of the OBE Processes}

This section examines the outcomes of implementing OBE ecosystem in the business school of the private education institution in Malaysia, its importance, challenges and some recommendations to manage these challenges.

Establishing an OBE system can be challenging without a proper OBE implementation plan (Gunarathne et al., 2019; Reich et al., 2019a; Spady \& Marshall, 1991). However, the implementation of the OBE system in the education sector in Malaysia is significant to (re)align the programmes, modules, teaching and learning methodologies, assessment and performance measurement that are deemed important to enhance students' learning experiences and improve the competencies of (potential) graduates (Kalianna \& Chandran, 2012).

From the OBE process and the evidence obtained, academics and students were informed of the outcomes from their courses.

This education institution employs a five-scale grading system:

Excellent, Good, Adequate, Weak and Poor. 
It was observed that the students' performance was measured more systematically and objectively using standardised rubrics, while academics were better informed on the performance of the students. Through this process, the academics were willing to make continuous improvement to their delivery methods and assessment as they were more receptive to the idea of evidence-informed outcomes. This was mainly due to constructive alignment that enabled students' performance to be measured more accurately that subsequently enhanced the quality of programmes and graduates. This is consistent with the findings by Almarghani and Mijatovic (2017); Barradell (2012); Dragoo and Barrows (2016); Reich et al. (2019a). As mentioned by Hill and Wang (2018), the implementation process is a team effort. The assessment feedback from colleagues and administrative staff helped improve the execution process with quality assurance and enhancement (Edström, 2008).

Gunarathne et al. (2019) supported the implementation of OBE approach in the accounting degree programme at a Sri Lankan public university. It was observed that the approach, as part of the quality assurance in the university, allowed various teaching and learning methodologies to be implemented, and ensured that the learning outcomes and expectations of the accounting professions were met. Additionally, it was observed that the students' ability to apply theoretical concepts in practical scenarios improved.

After implementing the OBE approaches, it was observed that some academics in this institution were willing to share various best practices and were open to adopting these new changes gradually. This demonstrates a continuous quality improvement activity that could improve the quality of courses and programmes. This finding is consistent with Kennedy and Birch (2020). However, some studies have also suggested that the OBE is more task-oriented and the results are quantified to show the relevant outcomes, for which it is only applicable to technical courses.

The use of constructive alignment in the OBE system reflects the support of a good quality teaching and learning system in education institutions. It helps academics identify the strengths and weaknesses in the syllabus, while assessing students through appropriate delivery methods (Rust, 2002). One of the challenges faced during the implementation of the OBE process in this business school was to 
recognise whether the academics were equipped with the necessary skills for constructive alignment. During the implementation of the OBE process, feedback from assessment data was given to academics and programme coordinators as a means to improve their courses and programmes. However, at the early stages of the OBE process, it was difficult for academics to accept constructive criticisms from the task force as they perceived themselves as expert of the subjectarea, while other academics were not trained as professional lecturers (Barradell, 2012; Kim \& Helms, 2016). Therefore, proper training and personalised consultation should be provided to academics to ensure that they are aware of the importance of the OBE process and can constructively (re)align their courses accordingly. Reward system can be established to grant recognition to academics who champion OBE.

When there is a change in the curriculum, the question then arises: can the quality of the syllabus, teaching and learning methodologies, and assessment be maintained? This issue was discussed by Kim and Helms (2016); and Djoundourian (2017), and asserts that the changes in academics and assessment may have an impact on the grading system. However, it can be deduced that with an established OBE system in an institution, the workload of academics will be lower in relation to resetting the learning outcomes of module. This may not be achievable if the academics have no prior knowledge or experience in $\mathrm{OBE}$.

Furthermore, with the standardised set of rubrics and proper setting of learning outcomes, the expectations for the performance of students and programmes will be better understood as students will be more willing to take ownership of their studies (Gunarathne et al., 2019; Matthews \& Mercer-Mapstone, 2018; Reich et al., 2019b). The programme coordinators were advised to be committed and apply the skills to assess the performance of students and programmes, and continue to monitor and review the programmes for necessary changes.

As stated by Reich et al. (2019a), one of the initial challenges to implement the OBE process is to convince the institution, academics and administrative staff about the idea as it can be a waste of their time and effort. Roller et al. (2003) and Djoundourian (2017) highlighted the significant expenses and efforts that were needed 
when obtaining accreditation or implementing the OBE process. It is prudent that when an institution is seeking accreditation or implementing the OBE process for quality assurance, the top management must have proper resource allocation and personnel to ensure the smooth running of the OBE system within the institution. This is an important investment to ensure good quality of courses, programmes and graduates. In addition, some education institutions have heralded its OBE process implementation as a selling point for staff recruitment, marketing and promotion, and industry linkages, as highlighted by Roller et al. (2003).

An effective assessment of learning outcomes may take years to be implemented. Apart from that, some academics faced increasing pressure when implementing OBE that had lowered their quality and creativity during syllabus and assessment delivery, as highlighted by Gunarathne et al. (2019). However, this notion was contradictory to the findings deduced by Matthews and Mercer-Mapstone (2018) and indicated different and creative pedagogical approaches that were included to facilitate scaffolding and progressive development of skillsets in the delivery of syllabus and assessment. This helped students build their interest and encouraged them to take ownership of their studies.

Kalianna and Chandran (2012) employed the Computerised Outcomes-Based Education System to assess the achievements of students in four courses' learning outcomes. The study emphasized the importance of continuous improvements in academics' delivery methodologies to enhance students' understanding on the course matter. This was easily accomplished with a computerised system; however, it is difficult to know the extent of the potential outcomes from the OBE process, and therefore, a manual system may be more appropriate at the initiation stage. The entire OBE process is an ongoing and evolving process that requires constant evaluation and review to achieve its stated objectives. Hence, transparency with the relevant stakeholders is important to obtain feedback and suggestions towards the development of the OBE system (Gunarathne et al., 2019; Hill \& Wang, 2018; Reich et al., 2019a).

Another challenge that was identified was differentiating between teaching and research. In higher education institutions, both teaching and research carry equal importance. However, if there is greater 
importance and emphasis towards research, academics will direct more of their efforts on research publications and less on students' development and learning experiences. For some academics, their main objectives are on the delivery of content to their students. Minimal effort goes into the preparation of content and delivery methods, where this produces inadequate or unreliable assessments that are prepared to help students understand the course content. Most academics prioritise research publications as these will help them get promotions, as suggested by Thian et al. (2018).

Reich et al. (2019a) stated that this issue is common among academics as most of them are resistant to change and are not inclined to share best practices to other academics. Therefore, to address this issue, reward systems should be established to engage academics in administrative work, and open communication should be in place to ensure transparency of information among academics and the relevant stakeholders. Progressions and changes need to be communicated clearly in order for everyone to have the right information.

Establishing an OBE system is essential in education institutions to ensure that the correct assessment is provided, and measures the students' performance accurately and reliably. Moreover, this is to ensure consistency in measurement. However, this study found that when there was a large classroom setting with more than one academic assigned to teach the course, consistency in implementing teaching and learning methodologies, and assessing students' performance became a challenge. Some academics tended to be biased towards students with better grades. Therefore, implementing a standardised set of rubrics for assessment may help solve the issues as this will reduce response bias in marking (Kim \& Helms, 2016), and would improve the performance of academics and students by incorporating evidence-informed teaching (Reich et al., 2019b). Academics should also be given opportunities to modify and standardise their syllabus, and teaching and learning methodologies to improve students' performance through constructive alignment activities (Gunarathne et al., 2019).

Quantitative information extracted from the OBE system is meaningless without further analysis of the programme and course levels. Students who score higher than the benchmark does not 
guarantee good learning experiences (Djoundourian, 2017; Kalianna \& Chandran, 2012). Moreover, without any improvements observed in the student learning and programmes, the OBE system may be viewed as another policy that needs to be constantly reviewed and examined, which may create frustration among academics (Aamodt et al., 2016). Hence, in assessing students' performance, academics need to consider the programme structure, delivery methodologies, assessment, and quality of the students. It would be meaningful if relevant comparisons can be made. The OBE system is established for student-centred learning, measurement and reporting purposes, and therefore, the responsibility lies with the academics, programme coordinators and Heads of Department to review the adjustments needed for programme and curriculum design/redesign through constructive alignment.

Hill and Wang (2018) and Reich et al. (2019a) suggested that the implementation of OBE approaches in the higher education institution is a team effort. Collaboration among administration, faculty/school and other stakeholders are needed to ensure that transparency and the incorporation of learning outcomes syllabus, delivery methods, and assessment are in place to meet the expectations of industry experts. Hence, continuous quality improvement on the courses and programmes must be maintained to produce sustainable outcomes.

\section{CONCLUSION}

Outcome-Based Education (OBE) refers to the process of improving students' learning experiences by achieving learning outcomes through curriculum design. The outcome of the OBE process is important to ensure that the education institutions can measure students' performance objectively and effectively; and provide assurance to relevant stakeholder on the quality and competency of graduates. The OBE process serves as an important tool to promote the quality of education, institutions, programmes and employability of students.

This study aims to discuss the implementation of the OBE process at a business school in a private education institution in Malaysia. During the implementation of the OBE process, the importance and challenges of the OBE process were observed and discussed, while 
some recommendations were made to improve the establishment of the OBE process.

This study theoretically contributes to the implementation and adoption of the OBE process at the business school. As the processes were discussed in detail, it is obvious that the OBE system may take years to be fully established, and would require significant effort from everyone in the education institution. However, due to the changes in expectations of the authority and stakeholders, the implementation of the $\mathrm{OBE}$ process has become mandatory for higher education institutions in Malaysia. The procedures detailed in this study to establish the OBE process will provide a practical guide to other education institutions in Malaysia, and around the world.

The OBE process is imperative in education institutions as it can assure the relevant stakeholders on the quality of (potential) graduates, and inspire curriculum (re)design within the institution. It can be regarded as a cyclical process for continuous quality improvement of the modules/programmes. This study highlighted the importance and challenges encountered during the implementation of OBE process, and provided recommendations to top management and academics for quality assurance and improvements. These recommendations would help solve the practical issues encountered that would ensure a stable and sustainable OBE process in the future.

This study also aims to inform both policy makers and accreditation bodies on the guidelines, standards and principles of the education qualification frameworks that have to be considered when implementing the OBE process. The standardised and achievable expectations, and benchmarks of these bodies will ensure the effectiveness of the OBE process and minimise resistance from education institutions during the implementation process (Gunarathne et al., 2019).

The theoretical and practical contributions, and implications provide avenues for further studies. This study was conducted based on document analyses and observations, which limited the generalisability of the findings (Gunarathne et al., 2019). For future studies, a comparison of multiple case studies approaches or survey methods with a greater sample size can be conducted. This would present a more comprehensive conclusion, whereby comparative 
studies can be done with different settings and education institutions. Furthermore, this study focused on ten undergraduate studies in the business school of a private higher education institution in Malaysia. Therefore, further studies can be conducted to include the implementation of the OBE process, its importance and challenges encountered in the science degree programmes or postgraduate study programmes, where a comparative study can be carried out across the disciplines.

\section{ACKNOWLEDGEMENT}

This research received no specific grant from any funding agency in the public, commercial, or not-for-profit sectors.

\section{REFERENCES}

Aamodt, P. O., Frølich, N., \& Stensaker, B. (2016). Learning outcomes - a useful tool in quality assurance? Views from academic staff. Studies in Higher Education, 43(4), 614624. https://doi:10.1080/03075079.2016.1185776

Almarghani, E. M., \& Mijatovic, I. (2017). Factors affecting student engagement in HEIs - it is all about good teaching. Teaching in Higher Education, 22(8), 940-956. https://doi:10.1080/1 3562517.2017 .1319808

Barradell, S. (2012). The identification of threshold concepts: A review of theoretical complexities and methodological challenges. Higher Education, 65(2), 265-276. https:// doi:10.1007/s10734-012-9542-3

Djoundourian, S. S. (2017). Assessment of learning in business education: Standardized or homegrown? Journal of Education for Business, 92(5), 238-244. https://doi:10.108 0/08832323.2017.1339662

Dragoo, A., \& Barrows, R. (2016). Implementing competency-based business curricula in higher education. Journal of Education for Business, 91(7), 374-379. https://doi:10.1080/08832323 .2016 .1237932

Edström, K. (2008). Doing course evaluation as if learning matters most. Higher Education Research \& Development, 27(2), 95-106. https://doi:10.1080/07294360701805234 
Gibbs, G., \& Habeshaw, T. (1992). Preparing to teach: An introduction to effective teaching in higher education. Technical \& Educational Services Ltd, Bristol.

Gibbs, G., \& Simpson, C. (2004). Conditions under which assessment supports students' learning. Learning and Teaching in Higher Education (1).

Gunarathne, N., Senaratne, S., \& Senanayake, S. (2019). Outcomebased education in accounting. Journal of Economic and Administrative Sciences, 36(1), 16-37. https://doi:10.1108/ jeas-08-2018-0093

Hill, L. M., \& Wang, D. (2018). Integrating sustainability learning outcomes into a university curriculum. International Journal of Sustainability in Higher Education, 19(4), 699720. https://doi:10.1108/ijshe-06-2017-0087

Kalianna, M., \& Chandran, S. D. (2012). Empowering students through outcome-based education (OBE). Research in Education, 87(1), 50-63. https://doi:10.7227/RIE.87.1.4.

Kember, D. (2001). Beliefs about knowledge and the process of teaching and learning as a factor in adjusting to study in higher education. Studies in Higher Education, 26(2), 205221. https://doi:10.1080/03075070120052116

Kennedy, M., \& Birch, P. (2020). Reflecting on outcome-based education for human services programs in higher education: A policing degree case study. Journal of Criminological Research, Policy and Practice, ahead-of-print(ahead-ofprint). https://doi:10.1108/jcrpp-12-2019-0071

Kim, D.-g., \& Helms, M. M. (2016). Assessing faculty bias in rating embedded assurance of learning assignments. Journal of Education for Business, 91(3), 159-165. https://doi:10.108 0/08832323.2016.1145624

Koh, K. C., George, S. R. K., Pak, J. W., Liow, Y. T., \& Khor, J. X. (2014). Role of community service as a curriculum delivery too in the outcome-based curriculum of the International Medical University, Malaysia. International E-Journal of Science, Medicine \& Education, 8(1), 24-31.

Malaysian Qualifications Agency. (2013). Guidelines to good practices: Assessment of students. Retrieved from https:// www2.mqa.gov.my/qad/v2/ggpnew.cfm

Malaysian Qualifications Agency. (2017). Code of Practice for Programme Accreditation (2 ${ }^{\text {nd }}$ Edition). Retrieved from https://www.mqa.gov.my/pv4/pubs_form.cfm 
Ministry of Finance Malaysia. (2017). 2018 Budget. Retrieved from

Percetakan Nasional Malaysia Berhad: http://www.treasury. gov.my/pdf/budget/speech/bs18.pdf

Ministry of Finance Malaysia. (2018). Budget 2019. Retrieved from Percetakan Nasional Malaysia

bs19.pdf

Berhad: http://www.treasury.gov.my/pdf/budget/speech/

Matthews, K. E., \& Mercer-Mapstone, L. D. (2018). Toward curriculum convergence for graduate learning outcomes: Academic intentions and student experiences. Studies in Higher Education, 43(4), 644-659. https://doi:10.1080/030 75079.2016.1190704

Reich, A. Z., Collins, G. R., DeFranco, A. L., \& Pieper, S. L. (2019a).A recommended closed-loop assessment of learning outcomes process for hospitality programs. International Hospitality Review, 33(1), 41-52. https://doi:10.1108/ihr-09-2018-0010 Reich, A.Z., Collins, G. R., DeFranco, A. L., \& Pieper, S. L. (2019b). A recommended closed-loop assessment of learning outcomes process for hospitality programs. International Hospitality Review, 33(1), 53-66. https://doi:10.1108/ihr-03-2019-0003

Roller, R. H., Andrews, B. K., \& Bovee, S. L. (2003). Specialized accreditation of business school: A comparison of alternative costs, benefits and motivations. Journal of Education for Business, 78(4), 197-204. https:// doi:10.1080/08832320309598601

Rust, C. (2002). The impact of assessment on student learning. Active Learning in Higher Education, 3(2), 145-158. doi: $10.1177 / 1469787402003002004$

Spady, W. G. (1994). Choosing outcomes of significance. Educational Leadership, 51(6), 18-22.

Spady, W. G., \& Marshall, K. J. (1991). Beyond traditional outcomebased education. Educational Leadership, 49(2), 67-72.

Thian, L. B., Ng, F. P., \& Ewe, J. A. (2018). Constructive alignment of graduate capabilities: Insights from implementation at a private university in Malaysia. Malaysian Journal of Learning and Instruction, 15(2), 111-142.

Vighnarajah, Wong, S. L., \& Abu Bakar, K. (2009). Qualitative findings of students' perception on practice of self-regulated strategies in online community discussion. Computers \& Education, 53(1), 94-103. https://doi:10.1016/j. compedu.2008.12.021 